Marquette University

e-Publications@Marquette

School of Dentistry Faculty Research and

Publications

Dentistry, School of

$2-1-2018$

\title{
Orthognathic Surgical Outcomes in Patients With and Without Craniofacial Anomalies
}

Zohra Metalwala

Marquette University

Christopher Okunseri

Marquette University, christopher.okunseri@marquette.edu

Steven Fletcher

University of Iowa

Veerasathpurush Allareddy

University of Iowa

Accepted version. Journal of Oral and Maxillofacial Surgery, Vol. 76, No. 2 (February 2018). DOI. (C) 2017 American Association of Oral and Maxillofacial Surgeons. Used with permission. 
Marquette University

e-Publications@Marquette

\section{Dentistry Faculty Research and Publications/School of Dentistry}

This paper is NOT THE PUBLISHED VERSION; but the author's final, peer-reviewed manuscript. The published version may be accessed by following the link in th citation below.

Journal of Oral and Maxillofacial Surgery, Vol. 76, No. 2 (February 2018): 436.e1-436.e8. DOI. This article is (C) Elsevier and permission has been granted for this version to appear in $\underline{\mathrm{e}-}$ Publications@Marquette. Elsevier does not grant permission for this article to be further copied/distributed or hosted elsewhere without the express permission from Elsevier.

\section{Orthognathic Surgical Outcomes in Patients with and without Craniofacial Anomalies}

\section{Zohra Metalwala}

Research Associate, Department of Clinical Services, Marquette University School of Dentistry, Milwaukee, WI

\section{Christopher Okunseri}

Professor and Director, Department of Clinical Services, Marquette University School of Dentistry, Milwaukee, WI

\section{Steven Fletcher}

Associate Professor and Program Director, Department of Oral and Maxillofacial Surgery, College of Dentistry and Dental Clinics, The University of lowa, lowa City, IA

Veerasathpurush Allareddy

Professor, Department of Orthodontics, and Collegiate Director of Craniofacial Clinical Research, College of Dentistry and Dental Clinics, The University of lowa, lowa City, IA

\section{Purpose}

The objective of this study is to examine hospitalization outcomes after orthognathic surgery. This study tests the hypothesis that patients with craniofacial anomalies have higher billed hospital charges, longer lengths of 
stay, and increased odds of development of infectious complications when compared with patients without craniofacial anomalies.

\section{Materials and Methods}

The Nationwide Inpatient Sample for the years 2012 and 2013 was used. All patients who underwent an orthognathic surgical procedure were selected. The primary independent variable of interest was presence of a congenital cleft and/or craniofacial anomaly. The outcome variables were the occurrence of complications, billed hospital charges, and length of stay. Multivariable logistic and linear regression models were used to examine the effect of the presence of craniofacial anomalies on outcomes.

\section{Results}

During the study period, a total of 16,515 patients underwent an orthognathic surgical procedure in the United States. Of these patients, 2,760 had a cleft and/or craniofacial anomaly. An infectious complication occurred in $7.4 \%$ of those with a craniofacial anomaly (compared with $0.6 \%$ of those without a craniofacial anomaly). The mean billed hospital charges in those with a craniofacial anomaly was $\$ 139,317$ (compared with $\$ 56,189$ in those without a craniofacial anomaly). The mean length of stay in the hospital in patients with a craniofacial anomaly was 8.8 days (compared with 1.8 days in those without a craniofacial anomaly). These differences in outcomes between patients with and patients without craniofacial anomalies were significant after we adjusted for patient- and hospital-level confounders.

\section{Conclusions}

Patients with a craniofacial anomaly are at higher risk of development of infectious complications, have higher hospital charges, and stay in the hospital for a longer duration after orthognathic surgery when compared with those without a craniofacial anomaly.

Orthognathic surgery is widely used to correct craniofacial skeletal disharmony. Craniofacial discrepancies can present as congenital anomalies in conjunction with syndromes or arise later in life as a result of an imbalance of growth between the maxilla and mandible. Depending on the severity of the skeletal discrepancy and the timing of the intervention, a number of treatment options are in vogue. In growing patients, early intervention such as growth modification with orthodontic treatment alone can be performed. In cases involving severe skeletal asymmetries, surgical intervention may be unavoidable. Generally, patients with congenital craniofacial anomalies present with maxillary and mandibular skeletal deformities that require an interdisciplinary collaboration between a surgeon and an orthodontist to correct the deformity. $\underline{1}, \underline{2}$ In some cases, patients may choose surgical intervention on an elective basis to improve esthetics, function, and speech. However, in patients with life-threatening severe craniofacial anomalies, surgical intervention may be required. In addition, surgical treatment can improve the psychosocial well-being of patients and their quality of life. $\underline{3}$, $\underline{4}$ However, even with documented evidence of the potential benefits and success of orthognathic surgery, patients and parents may still be reluctant to proceed because of concerns about the treatment outcomes, possible complications, length of hospitalization, and financial obligations associated with the procedure.

To our knowledge, this is the first study based on a national dataset that presents demographic estimates for patients undergoing orthognathic surgeryand the possible complications (eg, occurrence of infection), billed hospital charges, and length of stay separated into patients with and patients without craniofacial anomalies in the United States. This study tests the hypothesis that there is a difference in treatment complications between those with and those without craniofacial anomalies. We hypothesized that those with craniofacial anomalies 
would have higher billed hospital charges, longer lengths of stay, and increased odds of development of infectious complications when compared with those without craniofacial anomalies.

\section{Materials and Methods}

This is a retrospective secondary data analysis of the Nationwide Inpatient Sample (NIS) for the years 2012 and 2013. The NIS is the largest all-payer hospital database in the United States. ${ }^{5}$ It belongs to the Healthcare Cost and Utilization Project family of databases and is sponsored by the Agency for Healthcare Research and Quality. The NIS is a $20 \%$ stratified sample of all hospitalizations in the United States. Each hospitalization is assigned a weight variable that can be used to project all estimates to a nationally representative $100 \%$ of hospitalizations in the United States. Because our study used a publicly available database of the Healthcare Cost and Utilization Project-Agency for Healthcare Research and Quality and the activity was limited to the analysis of publicly available deidentified data, as per the Office of Human Subjects Protection of The University of lowa (protocols 201612753 and 201607755), the study did not meet the regulatory definition of human subjects research and did not require review by the institutional review board.

The study population comprised all patients who underwent an orthognathic surgical procedure in hospitals across the United States during the years 2012 and 2013. International Classification of Diseases, Ninth Revision, Clinical Modification (ICD-9-CM) procedure and diagnosis codes were used to identify those who underwent orthognathic surgery for specified facial skeletal problems (Tables 1 and $\underline{2}$ ), including those with a congenital cleft and/or craniofacial condition. $\underline{6}$

Table 1. Craniofacial Skeletal Problems for Which Patients Underwent Orthognathic Surgery

\begin{tabular}{|l|l|}
\hline Diagnostic Condition & ICD-9-CM Code \\
\hline Major anomalies of jaw size-unspecified & 524.00 \\
\hline Maxillary hyperplasia & 524.01 \\
\hline Mandibular hyperplasia & 524.02 \\
\hline Maxillary hypoplasia & 524.03 \\
\hline Mandibular hypoplasia & 524.04 \\
\hline Macrogenia & 524.05 \\
\hline Microgenia & 524.06 \\
\hline Excessive tuberosity of maxilla & 524.07 \\
\hline Other specified anomalies of jaw size & 524.09 \\
\hline $\begin{array}{l}\text { Unspecified anomalies of relation of jaw to cranial base-includes unspecified } \\
\text { prognathism or retrognathism }\end{array}$ & 524.10 \\
\hline Maxillary asymmetry & \\
\hline Other jaw asymmetry & 524.11 \\
\hline Other specified anomalies of relation of jaw to cranial base & 524.12 \\
\hline Unspecified anomaly of dental arch relation & 524.19 \\
\hline Angle Class I malocclusion & 524.20 \\
\hline Angle Class II malocclusion & 524.21 \\
\hline Angle Class III malocclusion & 524.22 \\
\hline Anterior open bite & 524.23 \\
\hline Posterior open bite & 524.24 \\
\hline Excessive overjet & 524.25 \\
\hline Crossbite & 524.26 \\
\hline Anomalies of interarch distance & 524.27 \\
\hline Other anomalies of dental arch relation & 524.28 \\
\hline Malocclusion- unspecified & 524.29 \\
\hline & 524.4 \\
\hline
\end{tabular}




\begin{tabular}{|c|c|}
\hline Alveolar maxillary hyperplasia & 524.71 \\
\hline Alveolar mandibular hyperplasia & 524.72 \\
\hline Alveolar maxillary hypoplasia & 524.73 \\
\hline Alveolar mandibular hypoplasia & 524.74 \\
\hline Occlusal plane deviation & 524.76 \\
\hline Zygomatic hypoplasia & 738.12 \\
\hline Other acquired deformity of head & 738.19 \\
\hline \multicolumn{2}{|l|}{ Craniofacial anomalies } \\
\hline Neurofibromatosis, type 1 (von Recklinghausen disease) & 237.71 \\
\hline Cleft lip and/or palate & $\begin{array}{l}\text { 749.0X, 749.1X, or } \\
749.2 X\end{array}$ \\
\hline Acromegaly & 253.0 \\
\hline $\begin{array}{l}\text { Congenital musculoskeletal deformities of skull, face, and jaw including } \\
\text {-Asymmetry of face } \\
\text { - Compression facies } \\
\text {-Depressions in skull } \\
\text { - Deviation of nasal septum, congenital } \\
\text { - Dolichocephaly } \\
\text {-Plagiocephaly } \\
\text {-Potter facies } \\
\text {-Squashed or bent nose, congenital }\end{array}$ & 754.0 \\
\hline Apert syndrome & 755.55 \\
\hline Cleidocranial dysostosis & 755.59 \\
\hline $\begin{array}{l}\text { Anomalies of skull and face bones including } \\
\text {-Absence of skull bones } \\
\text { - Acrocephaly } \\
\text { - Congenital deformity of forehead } \\
\text { - Craniosynostosis } \\
\text { - Crouzon disease } \\
\text { - Hypertelorism } \\
\text { - Imperfect fusion of skull } \\
\text { - Oxycephaly } \\
\text { - Platybasia } \\
\text { - Premature closure of cranial sutures } \\
\text {-Tower skull } \\
\text {-Trigonocephaly }\end{array}$ & 756.0 \\
\hline Ehlers-Danlos syndrome & 756.83 \\
\hline Marfan syndrome & 759.82 \\
\hline Congenital malformation syndromes affecting multiple systems & 759.89 \\
\hline
\end{tabular}

Abbreviation: ICD-9-CM, International Classification of Diseases, Ninth Revision, Clinical Modification.

Table 2. Types of Surgical Procedures

\begin{tabular}{|l|l|}
\hline Procedure (ICD-9-CM Procedure Code) & No. of Patients* \\
\hline Closed osteoplasty (osteotomy) of mandibular ramus (76.61) & 505 \\
\hline Open osteoplasty (osteotomy) of mandibular ramus (76.62) & 5,250 \\
\hline Osteoplasty (osteotomy) of body of mandible (76.63) & 1,130 \\
\hline Other orthognathic surgery on mandible (76.64) & 3,570 \\
\hline Segmental osteoplasty (osteotomy) of maxilla (76.65) & 8,540 \\
\hline Total osteoplasty (osteotomy) of maxilla (76.66) & 2,965 \\
\hline Reduction genioplasty (76.67) & 360 \\
\hline
\end{tabular}




\begin{tabular}{|l|l|}
\hline Augmentation genioplasty (76.68) & 2,000 \\
\hline Other facial bone repair (76.69) & 2,160 \\
\hline
\end{tabular}

Abbreviation: ICD-9-CM, International Classification of Diseases, Ninth Revision, Clinical Modification. $*$ A patient may have had more than 1 procedure performed during the hospitalization.

The primary independent variable of interest was presence of a congenital cleft and/or craniofacial anomaly. The study population was divided into 2 groups: those with and those without a craniofacial anomaly. The conditions and specific ICD-9-CM diagnosis codes used to identify craniofacial anomalies included the following: neurofibromatosis, type 1 (237.71); cleft lip and/or palate(749.0X, 749.1X, or

749.2X); acromegaly (253.0); congenital musculoskeletal deformities of skull, face, and jaw (754.0); Apert syndrome (755.55); cleidocranial dysostosis (755.59); anomalies of skull and face bones (including absence of skull bones, acrocephaly, congenital deformity of forehead, craniosynostosis, Crouzon disease, hypertelorism, imperfect fusion of skull, oxycephaly, platybasia, premature closure of cranial sutures, tower skull, and trigonocephaly) (756.0); Ehlers-Danlos syndrome (756.83); Marfan syndrome(759.82); and congenital malformation syndromes affecting multiple systems (759.89). The outcome variables of interest included the occurrence of complications, billed hospital charges, and length of stay. Complications were identified based on the existing literature using the NIS databases. $\underline{7} \underline{8}, \underline{9}$ Two composite variables (occurrence of an infectious complication and occurrence of any type of complication) were created for assessing complications occurring in the study population. Billed hospital charges were adjusted to year 2013 levels using the hospital costs inflation indicator from the Bureau of Labor Statistics. $\frac{10}{}$ Other variables examined included age, gender, race, insurance status, comorbid burden (based on NIS severity files), household income level, hospital location and teaching status, number of surgical procedures, and type of admission.

\section{Statistical Analysis}

The association between the primary independent variable (presence vs absence of craniofacial anomaly) and the occurrence of an infectious complication was examined by multivariable logistic regression analysis. The association between the primary independent variable and the occurrence of at least 1 type of complication was examined by multivariable logistic regression analysis. The association between the primary independent variable and hospital charges or length of stay was examined by multivariable linear regression models. In all the regression models, we adjusted for the confounding effects of age, gender, race, type of admission, comorbid burden, insurance status, hospital region, household income level, hospital location and teaching status, number of procedures, and year of surgery. We also adjusted for the effects of clustering of outcomes within hospitals. In the regression models, the Taylor linearization method was used to compute the variances and standard errors. We adjusted for clustering effects by using the stratum to which the hospital belonged and the hospital identifier in the "nest" statement. All statistical analyses were conducted using SAS software (version 9.4; SAS Institute, Cary, NC) and SAS-callable SUDAAN software (version 11.0.1; RTI International, Research Triangle Park, NC).

\section{Results}

During the study period, a total 16,515 patients underwent an orthognathic surgical procedure in the United States. Of these patients, 2,760 had a cleft and/or craniofacial anomaly. The characteristics of the study population are summarized in Table 3. The mean age of patients with a craniofacial anomaly was 13.8 years (compared with 25.2 years in those without a craniofacial anomaly). Female patients comprised a greater proportion of patients, and white race was the predominant race, followed by Hispanic, black, other race or multiracial, and Asian or Pacific Islander. Most patient treatment procedures were performed on an elective basis. Of the patients with a craniofacial anomaly, 15.2\% underwent surgery on an emergency or urgent basis 
(compared with 5.5\% of those without a craniofacial anomaly). Private insurance was the predominant payer in both groups. Of those without a craniofacial anomaly, $76.5 \%$ did not have a pre-existing comorbid condition, whereas $72.5 \%$ of those with a craniofacial anomaly had a comorbid condition. The surgical procedure was performed in an urban teaching hospital in $91.7 \%$ of patients with a craniofacial anomaly (compared with $77.5 \%$ of patients without a craniofacial anomaly).

Table 3. Characteristics of Patients

\begin{tabular}{|c|c|c|}
\hline Characteristic & $\begin{array}{l}\text { Patients Without Craniofacial } \\
\text { Anomalies }(n=13,755)\end{array}$ & $\begin{array}{l}\text { Patients With Craniofacial } \\
\text { Anomalies }(n=2,760)\end{array}$ \\
\hline \multicolumn{3}{|l|}{ Gender } \\
\hline Male & $42.2 \%$ & $48.2 \%$ \\
\hline Female & $57.8 \%$ & $51.8 \%$ \\
\hline \multicolumn{3}{|l|}{ Race } \\
\hline White & $67.2 \%$ & $60.4 \%$ \\
\hline Black & $6.6 \%$ & $6.2 \%$ \\
\hline Hispanic & $12.4 \%$ & $20.9 \%$ \\
\hline Asian or Pacific Islander & $6.1 \%$ & $5.3 \%$ \\
\hline Native American & $0.4 \%$ & $1 \%$ \\
\hline Other & $7.3 \%$ & $6.2 \%$ \\
\hline \multicolumn{3}{|l|}{ Type of admission } \\
\hline Emergency or urgent & $5.5 \%$ & $15.2 \%$ \\
\hline Elective & $94.5 \%$ & $84.8 \%$ \\
\hline \multicolumn{3}{|l|}{ Insurance status } \\
\hline Medicare & $1.6 \%$ & $0.9 \%$ \\
\hline Medicaid & $14.2 \%$ & $25.9 \%$ \\
\hline Private & $74.8 \%$ & $64.7 \%$ \\
\hline Uninsured & $3.6 \%$ & $4 \%$ \\
\hline Other insurance & $5.9 \%$ & $4.5 \%$ \\
\hline \multicolumn{3}{|l|}{ Household income level } \\
\hline Quartile 1 & $15.2 \%$ & $18.3 \%$ \\
\hline Quartile 2 & $19.6 \%$ & $24.5 \%$ \\
\hline Quartile 3 & $27.6 \%$ & $25 \%$ \\
\hline Quartile 4 & $37.6 \%$ & $32.2 \%$ \\
\hline \multicolumn{3}{|l|}{ Comorbid burden } \\
\hline 0 & $76.5 \%$ & $72.5 \%$ \\
\hline 1 & $16.5 \%$ & $16.7 \%$ \\
\hline 2 & $5.2 \%$ & $7.6 \%$ \\
\hline$\geq 3$ & $1.8 \%$ & $3.2 \%$ \\
\hline \multicolumn{3}{|l|}{$\begin{array}{l}\text { Hospital location and } \\
\text { teaching status }\end{array}$} \\
\hline Rural hospital & $2.3 \%$ & $0 \%$ \\
\hline Urban nonteaching hospital & $20.2 \%$ & $8.3 \%$ \\
\hline Urban teaching hospital & $77.5 \%$ & $91.7 \%$ \\
\hline \multicolumn{3}{|l|}{ No. of procedures } \\
\hline 1 & $46.8 \%$ & $69.2 \%$ \\
\hline 2 & $42.2 \%$ & $25.4 \%$ \\
\hline$>2$ & $11 \%$ & $5.4 \%$ \\
\hline \multicolumn{3}{|l|}{ Age, yr } \\
\hline Mean & 25.2 & 13.8 \\
\hline
\end{tabular}


The occurrence of different types of complications is summarized in Table 4. Overall, the complication rate in patients with a craniofacial anomaly was $10.7 \%$ (compared with $2.5 \%$ in those without a craniofacial anomaly). Of those with a craniofacial anomaly, $7.4 \%$ had an infectious complication (compared with $0.6 \%$ of those without a craniofacial anomaly). The most frequently reported complications occurring in those with a craniofacial anomaly included bacterial infection (3.4\%); iatrogenically induced complications such as accidental puncture, laceration, or pneumothorax (1.8\%); hemorrhage (1.6\%); mycosis $(1.4 \%)$;

and septicemia (1.3\%). All other complications in those with a craniofacial anomaly occurred in fewer than $1 \%$ of patients. In those without a craniofacial anomaly, all the complications occurred in fewer than $1 \%$ of patients. Billed hospital charges and length of stay in the hospital are presented in Table 5. The mean billed hospital charges in patients with a craniofacial anomaly was $\$ 139,317$ (compared with $\$ 56,189$ in those without a craniofacial anomaly). The mean length of stay in the hospital in those with a craniofacial anomaly was 8.8 days (compared with 1.8 days in those without a craniofacial anomaly).

Table 4. Complications

\begin{tabular}{|l|l|l|}
\hline Type of Complication & $\begin{array}{l}\text { Patients Without Craniofacial } \\
\text { Anomalies (n= 13,755) }\end{array}$ & $\begin{array}{l}\text { Patients With Craniofacial } \\
\text { Anomalies (n = 2,760) }\end{array}$ \\
\hline Decubitus ulcer & DS & $0.5 \%$ \\
\hline Septicemia & DS & $1.3 \%$ \\
\hline Bacterial infection & DS & $3.4 \%$ \\
\hline Mycosis & $0.2 \%$ & $1.4 \%$ \\
\hline Other infection & DS & $0.7 \%$ \\
\hline Postoperative pneumonia & $0.4 \%$ & $3.1 \%$ \\
\hline Nonhealing wound & DS & DS \\
\hline Hemorrhage & $0.6 \%$ & $1.6 \%$ \\
\hline latrogenically induced & $0.9 \%$ & $1.8 \%$ \\
\hline Vascular complication & $0 \%$ & $0 \%$ \\
\hline Urinary system complication & $\mathrm{DS}$ & $\mathrm{DS}$ \\
\hline $\begin{array}{l}\text { Digestive system } \\
\text { complication }\end{array}$ & $0 \%$ & $0 \%$ \\
\hline $\begin{array}{l}\text { Respiratory system } \\
\text { complication }\end{array}$ & $0.1 \%$ & $0.7 \%$ \\
\hline Nervous system complication & $0.1 \%$ & $0.4 \%$ \\
\hline Cardiac system complication & $0.1 \%$ & $\mathrm{DS}$ \\
\hline $\begin{array}{l}\text { Any type of infectious } \\
\text { complication }\end{array}$ & $0.6 \%$ & $7.4 \%$ \\
\hline Any type of complication & $2.5 \%$ & $10.7 \%$ \\
\hline Abrevation: DS, discharge & & \\
\hline
\end{tabular}

Abbreviation: DS, discharge information suppressed because of individual cell count of 10 or fewer.

Table 5. Length of Stay and Hospital Charges

\begin{tabular}{|l|l|l|l|l|l|l|}
\hline & $\begin{array}{l}\text { Patients Without } \\
\text { Craniofacial Anomalies }\end{array}$ & & $\begin{array}{l}\text { Patients With } \\
\text { Craniofacial } \\
\text { Anomalies }\end{array}$ & & \\
\hline & Mean & $\begin{array}{l}\mathbf{9 5 \%} \text { CL for } \\
\text { Mean }\end{array}$ & SEM & Mean & $\begin{array}{l}\mathbf{9 5 \%} \text { CL for } \\
\text { Mean }\end{array}$ & SEM \\
\hline $\begin{array}{l}\text { Length of } \\
\text { stay, days }\end{array}$ & 1.8 & $1.72-1.96$ & 0.06 & 8.8 & $7.19-10.36$ & 0.80 \\
\hline
\end{tabular}




\begin{tabular}{|l|l|l|l|l|l|l|}
\hline $\begin{array}{l}\text { Hospital } \\
\text { charges, } \$\end{array}$ & 56,189 & $\begin{array}{l}53,636- \\
58,741\end{array}$ & 1,300 & 139,317 & $\begin{array}{l}120,912- \\
157,723\end{array}$ & 9,332 \\
\hline
\end{tabular}

Abbreviations: $\mathrm{CL}$, confidence limit; $\underline{\mathrm{SEM}}$, standard error of mean.

Results of estimates from the multivariable regression models are presented in Table 6. After adjustment for the confounding effects of age, gender, race, type of admission, comorbid burden, insurance status, hospital region, household income level, hospital location and teaching status, number of procedures, and year of surgery, patients with a craniofacial anomaly had a significantly higher odds of development of infectious complications (odds ratio, 3.82; 95\% confidence interval $[\mathrm{Cl}], 1.90-7.64 ; P<.0001$ ); a significantly higher odds of development of at least 1 of any type of complication (odds ratio, 2.72;95\% Cl, 1.67-4.44; $P<.0001$ ); significantly higher hospitalization charges ( $\beta$ coefficient estimate, $0.5210 ; 95 \% \mathrm{Cl}, 0.4319-0.6101 ; P<.0001$ ); and a significantly longer length of stay in the hospital ( $\beta$ coefficient estimate, $0.6452 ; 95 \% \mathrm{Cl}, 0.5473-0.7431 ; P<.0001$ ) when compared with those without a craniofacial anomaly.

Table 6. Summary of Estimates From Multivariable Regression Models*

\begin{tabular}{|l|l|l|l|l|}
\hline Outcome & $\begin{array}{l}\text { Presence of Craniofacial } \\
\text { Anomalies }\end{array}$ & $\begin{array}{l}\text { OR or Parameter } \\
\text { Estimate }\end{array}$ & $\mathbf{9 5 \%} \mathbf{C l}$ & PValue \\
\hline Infectious complication & Yes & OR, 3.82 & $1.90-7.64$ & $<.0001$ \\
\hline & No & Reference & & \\
\hline $\begin{array}{l}\text { Any type of } \\
\text { complication }\end{array}$ & Yes & OR, 2.72 & $1.67-4.44$ & $<.0001$ \\
\hline & No & Reference & & \\
\hline Hospital charges & Yes & $\begin{array}{l}\text { Parameter estimate, } \\
0.5210\end{array}$ & $\begin{array}{l}0.4319- \\
0.6101\end{array}$ & $<.0001$ \\
\hline & No & Reference & & \\
\hline Length of stay & Yes & $\begin{array}{l}\text { Parameter estimate, } \\
0.6452\end{array}$ & $\begin{array}{l}0.5473- \\
0.7431\end{array}$ & $<.0001$ \\
\hline & No & Reference & & \\
\hline
\end{tabular}

Abbreviation: $\mathrm{Cl}$, confidence interval; OR, odds ratio.

$*$ Regression models were adjusted for the confounding effects of age, gender, race, type of admission, comorbid burden, insurance status, hospital region, household income level, hospital location and teaching status, number of procedures, and year of surgery.

\section{Discussion}

The aim of this study was to report the nationwide demographic estimates and potential rates of complications for patients undergoing orthognathic surgerysubdivided into those with and those without craniofacial anomalies in the United States. This report is the first of its kind to provide a comprehensive estimate of the prevalence of orthognathic surgery based on gender, race, patient age, type of admission, insurance status, comorbid burden, and hospital type, along with postoperative complications, lengths of stay, and hospital charges. The female-to-male ratio was 1.37:1 for patients without anomalies and 1.07:1 for patients with anomalies. These findings are in line with data from a 2008 NIS data review including all patients undergoing orthognathic surgery. ${ }^{11}$ Information about race or ethnicity was not reported by 5 states in the NIS database, and in another 1,175 hospitalizations, patients selected "other race" in our review. The reported data showed that most patients in both groups were white ( $67.2 \%$ of those without and $60.4 \%$ of those with anomalies), followed by Hispanic ( $12.4 \%$ of those without and $20.9 \%$ of those with anomalies) and black (6.6\% of those without and $6.2 \%$ of those with anomalies). 
Data from the largest all-payer nationally representative hospital discharge database was used to examine the prevalence and predictors of 15 different types of systemic complications. Regarding these 15 types of complications, patients without craniofacial anomalies had 8 types of complications (decubitus ulcers, septicemia, bacterial infections, other infections, nonhealing wounds, vascular complications, urinary system complications, and digestive systemcomplications) that either did not occur or for which discharge information was suppressed because of an individual cell count of 10 patients or fewer. The remaining 7 types of complications (mycosis, postoperative pneumonia, hemorrhage, iatrogenically induced, respiratory system complications, nervous system complications, and cardiac system complications) occurred in fewer than $1 \%$ of patients. For patients with craniofacial anomalies, there were 5 types of complications (nonhealing wounds, vascular complications, urinary system complications, digestive system complications, and cardiac system complications) that either did not occur or for which discharge information was withheld; 4 types of complications (decubitus ulcers, other infections, respiratory system complications, and nervous system complications) occurred in fewer than $1 \%$ of patients; 4 types of complications (septicemia, mycosis, hemorrhage, and iatrogenically induced) occurred in between $1 \%$ and $2 \%$ of patients; and 2 types of complications (bacterial infections and postoperative pneumonia) occurred in $3 \%$ of patients or more. For patients without craniofacial anomalies, the 3 most common types of complications were iatrogenically induced $(0.9 \%)$, hemorrhage $(0.6 \%)$, and postoperative pneumonia $(0.4 \%)$. In patients with craniofacial anomalies, the 3 most common types of complications were bacterial infections (3.4\%), postoperative pneumonia (3.1\%), and iatrogenically induced (1.8\%). Overall, patients without craniofacial anomalies had a prevalence of infectious complications of $0.6 \%$ and a prevalence of complications of any type of $2.5 \%$. Patients with craniofacial anomalies had a prevalence of infectious complications of $7.4 \%$ and a prevalence of any type of complication of $10.7 \%$. These findings indicate that patients undergoing orthognathic surgery with craniofacial anomalies have an increased odds of complications compared with those without craniofacial anomalies.

In one study, age was independently associated with 4 different types of complications and the overall complication rate in patients with craniofacial anomalies. $\underline{7}$ With an increase in age, there were lower odds of bacterial infections, "other" infections, respiratory complications, postoperative pneumonia, and at least 1 of the 15 complications. This finding indicates that better outcomes could be realized when orthognathic surgical procedures were performed in older patients. However, this may not be possible because patients may need life-saving procedures, such as mandibular advancement, to open airways shortly after birth. This corresponds with our finding that the average age was 13.8 years in patients with craniofacial anomalies and 25.2 years in patients without anomalies. Furthermore, admission to undergo surgery occurred on an emergency or urgent basis in $15.2 \%$ of patients with craniofacial anomalies but only $5.5 \%$ of those without anomalies. This finding suggests that age may be an increased risk factor for patients with craniofacial anomalies that may be unavoidable.

Generally, the correction of skeletal discrepancies requires the simultaneous advancement of 1 jaw and the setback of the opposing jaw. In patients without craniofacial anomalies, 6,437 hospitalizations (46.8\%) involved only 1 procedure; 5,804 hospitalizations (42.2\%) involved 2 procedures; and 1,513 hospitalizations (11\%) involved 3 or more procedures. An interesting finding was that in patients with craniofacial anomalies, 1,909 hospitalizations (69.2\%) involved 1 procedure; 701 hospitalizations (25.4\%) involved 2 procedures; and 149 hospitalizations (5.4\%) involved 3 or more procedures.

The mean hospital length of stay was 1.8 days for patients without a craniofacial anomaly and 8.8 days for patients with a craniofacial anomaly. Previous work by Venugoplan and colleagues $\underline{11}$ that examined length of stay of all patients undergoing orthognathic surgery using NIS data for 2008 reported an average length of stay of 2.95 days, consistent with the findings of other authors. Allareddy ${ }^{7}$ used NIS data from 2004-2010 to evaluate length of stay for patients with craniofacial anomalies divided into those without and those with complications. 
He found that the median length of stay in the hospital was 1.5 days for patients without complications versus 11.2 days for patients with complications. He concluded that the highly skewed nature of length of stay was a result of a relatively smaller proportion of patients who were hospitalized for a prolonged duration. Furthermore, patients with complications tended to have longer lengths of stay. Length of stay is associated with increased hospital charges. In our study, the mean hospital charge was $\$ 56,189$ for patients without craniofacial anomalies and $\$ 139,317$ for those with craniofacial anomalies. Costs can be affected by surgical difficulty, complications that arise during surgery, and the quality of patient care.12, 13 Furthermore, hospital characteristics (eg, teaching vs nonteaching status, large-bed vs small-bed hospital, or hospital ownership), along with geographic location, can affect the fees.

Teaching hospitals are associated with improved outcomes for patients who need complex elective care.14, 15, 16 Accordingly, a review of NIS data from 2000-2008 found insurance status and comorbid disease burden to be significant patient-level predictors of being treated in a teaching hospital. ${ }^{17}$ Furthermore, highvolume and teaching hospitals have been identified as predictors of improved outcomes by several studies examining hospitalized patients undergoing surgical procedures for better quality of care in terms of reduced mortality rates, lower hospital readmission rates, fewer complications and/or adverse events, better management of complications and adverse events when they occur, better economics in terms of lower hospitalization charges or costs, and shorter durations of stay in the hospital.18, 19, 20, 21, 22, 23 This suggests that a high number of similar procedures performed by a hospital has a positive correlation to successful outcomes.24, 25 Perhaps for these reasons, teaching hospitals attract a higher case-severity mix of patients compared with nonteaching hospitals.14, 26 In accordance with the previous findings, in patients without craniofacial anomalies, 305 hospitalizations (2.3\%) were performed in rural hospitals; 2,778 hospitalizations (20.2\%) occurred in urban nonteaching hospitals; and 10,660 hospitalizations (77.5\%) were performed in urban teaching hospitals. Likewise, in patients with craniofacial anomalies, 0 hospitalizations occurred in rural hospitals and 229 hospitalizations (8.3\%) were performed in urban nonteaching hospitals, whereas the great majority, or 2,530 hospitalizations (91.7\%), were performed in urban teaching hospitals.

The comorbid burden can increase the risk of infectious complications because these patients are likely to be in a medically compromised condition. Of the patients without anomalies, $76.5 \%$ did not have any comorbidities, $16.5 \%$ had $1,5.2 \%$ had 2 , and $1.8 \%$ had 3 or more. Of the patients with craniofacial anomalies, $72.5 \%$ did not have any comorbidities, $16.7 \%$ had $1,7.6 \%$ had 2 , and $3.2 \%$ had 3 or more. In previous studies, an increased comorbid burden was associated with an increased risk of complications. It is important to note that the frequency and type of complications also can be affected by the surgical site, duration of surgery, surgical approach, wound contamination, and surgeon's expertise. $\underline{\underline{11}}$

Reduced insurance reimbursement has been suggested to be the reason for the reduction in orthognathic surgical procedures in the past 2 decades.27, 28However, in a comparison of the number of surgical procedures reported in the NIS for 2008 versus 2012-2013, the number of orthognathic surgical procedures performed

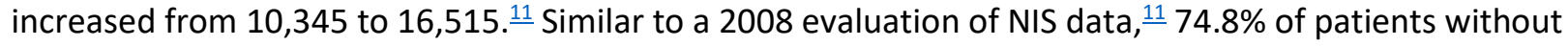
craniofacial anomalies and $64.7 \%$ of patients with craniofacial anomalies had private insurance in our study. However, in 2008 Medicaid covered 9.1\% of hospitalization (941). In 2012-2013, it reimbursed 14.2\% of hospitalizations $(1,953)$ for patients without anomalies and $25.9 \%$ of hospitalizations $(714)$ for patients without craniofacial anomalies.

Our study should be interpreted based on the following limitations: First, the aforementioned complications were identified using ICD-9-CM codes, which could prevent identification of localized complications addressed in multiple single-center studies. These studies typically examine the type of surgery, practice characteristics, heterogeneity of the study population, preoperative protocol, and duration of postoperative follow-up and report a range of complications. Therefore, postoperative complications may be underestimated in our study 
because some complications may be managed on an outpatientbasis and not reported in the database used. Nonetheless, our study provides the most comprehensive national overview of complications available. Second, in this retrospective secondary discharge data analysis, only associations were identified, and a true cause-andeffect relationship cannot be established. The risk adjustment that was conducted in the multivariable regression models was limited to the set of patient- and hospital-level confounders available in the NIS database. Finally, we used hospital charges as one of our outcome variables. The hospital charges do not reflect the "true costs" involved in delivering care. One way to estimate costs is to use hospital charge-to-cost ratio estimates. However, these are not consistently calculated across all hospitals and tend to vary with the hospital and comparative peer group. - Hence, the costs were not computed in this study. Despite these limitations, our study findings are valuable because the results can be generalized to the entire United States and identify areas in the process-of-care pathways that merit further investigation to improve quality of care delivered to patients undergoing orthognathic surgery.

In conclusion, patients with a craniofacial anomaly are at higher risk of development of infectious complications, have higher hospital charges, and stay in the hospital for a longer duration after orthognathic surgery when compared with those without a craniofacial anomaly.

\section{References}

$\underline{1}$ K.E. Kahnberg, C. Hagberg Orthognathic surgery in patients with craniofacial syndrome. I. A 5-year overview of combined orthodontic and surgical correction J Plast Surg Hand Surg, 44 (2010), p. 282

2 S. Oberoi, W.Y. Hoffman, K. Vargervik Craniofacial team management in Apert syndrome Am J Orthod Dentofacial Orthop, 141 (Suppl) (2012), p. S82

3 S.J. Kim, M.R. Kim, S.W. Shin, et al. Evaluation on the psychosocial status of orthognathic surgery patients Oral Surg Oral Med Oral Pathol Oral Radiol Endod, 108(2009), p. 828

$\leq$ C. Murphy, G. Kearns, D. Sleeman, et al. The clinical relevance of orthognathic surgery on quality of life Int J Oral Maxillofac Surg, 40 (2011), p. 926

$\underline{5}$ Healthcare Cost and Utilization Project (HCUP), Agency for Healthcare Research and Quality Nationwide Inpatient Sample Available at: https://www.hcup-us.ahrq.gov/nisoverview.jsp, Accessed 22nd Feb 2017

$\underline{6}$ Centers for Disease Control and Prevention, Classification of diseases, functioning, and disability International Classification of Diseases, Ninth Revision, Clinical Modification (ICD-9-CM) Available at:https://www.cdc.gov/nchs/icd/icd9cm.htm, Accessed 6th Mar 2014

$\underline{7}$ V. Allareddy Orthognathic surgeries in patients with congenital craniofacial anomalies: Profile and hospitalization outcomes Cleft Palate Craniofac J, 52 (2015), p. 698

$\underline{8}$ M.K. Lee, T.B. Dodson, N.Y. Karimbux, et al. Effect of occurrence of infection-related never events on length of stay and hospital charges in patients undergoing radical neck dissection for head and neck cancer Oral Surg Oral Med Oral Pathol Oral Radiol, 116 (2013), p. 147

9 V. Allareddy Prevalence and impact of complications on hospitalization outcomes following surgical repair for craniosynostosis J Oral Maxillofac Surg, 72 (2014), p. 2522

10 Bureau of Labor Statistics Consumer Price Index Inflation rate calculator for hospital inpatient care Available at: http://www.bls.gov/data/inflation calculator.htm, Accessed 16th Sep 2016

11 S.R. Venugoplan, V. Nanda, K. Turkistani, et al. Discharge patterns of orthognathic surgeries in the United States J Oral Maxillofac Surg, 70 (2012), p. e77

12 S. Kumar, A.C. Williams, A.J. Ireland, J.R. Sandy Orthognathic cases: What are the surgical costs? Eur J Orthod, 30 (2008), p. 31

13 G.A. Lombardo, M.H. Karakourtis, R.P. White The impact of clinical practice patterns on hospital charges for orthognathic surgery Int J Adult Orthodon Orthognath Surg, 9 (1994), p. 251

14 J. Kupersmith Quality of care in teaching hospitals: A literature review Acad Med, 80 (2005), p. 458 
15 J.B. Dimick, J.A. Cowan, L.M. Colletti, G.R. Upchurch Hospital teaching status and outcomes of complex surgical procedures in the United States Arch Surg, 139 (2004), p. 137

16 J.H. Silber, P.R. Rosenbaum, P.S. Romano, et al. Hospital teaching intensity, patient race, and surgical outcomes Arch Surg, 144 (2009), p. 113

17 V. Allareddy, M.B. Ackerman, S.R. Venugopalan, et al. Longitudinal trends in discharge patterns of orthognathic surgeries: Is there a regionalization of procedures in teaching hospitals? Oral Surg Oral Med Oral Pathol Oral Radiol, 115 (2013), p. 583

18 C.B. Begg, L.D. Cramer, W.J. Hoskins, M.F. Brennan Impact of hospital volume on operative mortality for major cancer surgery JAMA, 280 (1998), p. 1747

19 V. Allareddy, B.R. Konety Specificity of procedure volume and in-hospital mortality association Ann Surg, 246 (2007), p. 135

20 B.R. Konety, V. Allareddy, S. Modak, B. Smith Mortality after major surgery for urologic cancers in specialized urology hospitals: Are they any better? J Clin Oncol, 24 (2006), p. 2006

21 J.B. Dimick, P.J. Pronovost, J.A. Cowan, P.A. Lipsett Surgical volume and quality of care for esophageal resection: Do high-volume hospitals have fewer complications? Ann Thorac Surg, 75 (2003), p. 337

$\underline{22}$ B.R. Konety, V. Allareddy, H. Herr Complications after radical cystectomy: Analysis of population-based data Urology, 68 (2006), p. 58

23 P.P. Goodney, T.A. Stukel, F.L. Lucas, et al. Hospital volume, length of stay, and readmission rates in highrisk surgery Ann Surg, 238 (2003), p. 161

24 A.B. Flood, W.R. Scott, W. Ewy Does practice make perfect? Part I: The relation between hospital volume and outcomes for selected diagnostic categories Med Care, 22 (1984), p. 98

25 A.B. Flood, W.R. Scott, W. Ewy Does practice make perfect? Part II: The relation between volume and outcomes and other hospital characteristics Med Care, 22 (1984), p. 115

26 J.Z. Ayanian, J.S. Weissman Teaching hospitals and quality of care: A review of the literature Milbank Q, 80 (2002), p. 569

27 J.E. Zins, J. Bruno, A. Moreira-Gonzalez, J. Bena Orthognathic surgery: Is there a future? Plast Reconstr Surg, 116 (2005), p. 1442

28 J.E. Zins, C.M. Morrison, A.M. Gonzalez, et al. Follow-up: Orthognathic surgery. Is there a future? A national survey Plast Reconstr Surg, 122 (2008), p. 555

This study was funded by an American Association of Orthodontists Foundation Biomedical Research Award grant (awarded to V.A.).

Conflict of Interest Disclosures: None of the authors have any relevant financial relationship(s) with a commercial interest.

(c) 2017 American Association of Oral and Maxillofacial Surgeons 